\title{
DEL YO PIENSO AL YO SOY: UNA CONTRADICCIÓN DEL ESPÍRITU ROMÁNTICO
}

\author{
Juan Sebastián Ballén R. ${ }^{1}$ \\ Universidad Santo Tomás
}

Recibido: febrero 24 de 2005

Aprobado: mayo 6 de 2005

\section{Resumen}

En el presente texto cuestionaré los alcances de la autonomía del hombre moderno, afirmada desde el comienzo por la cogitación cartesiana, entrando en contradicción, y por tanto en crisis, con hombres poetas y filósofos del siglo XVIII, quienes buscan afirmarse desde una egoidad concreta, bien sea que se la entienda en perspectiva inclusiva hacia la totalidad o en la perspectiva contraria fijada por el aislamiento del ego con respecto al todo. El desarrollo de la presente cuestión iniciará con los aportes teleológicos que hizo Goethe en el campo de la ciencia. Sumándose a este propósito pasaré al texto "El más antiguo programa del sistema del idealismo alemán". Este texto, que se atribuye a los años de juventud de Hegel, Schelling y Hölderlin, representa un aspecto programático del idealismo alemán que tiene claras pretensiones de corporalizar la autonomía racional del hombre moderno. Finalmente me acercare al fenómeno del desencanto que produjo la irrealización del ego en la totalidad, quedando como fragmento de existencia el Yo soy que refleja la condición del hombre romántico. Para esto me he valido de Kierkegaard y su aporte al problema de la conciencia de sí, y de la figura de Rascolnikov, protagonista de la obra Crimen y castigo de Dostoievsky.

\section{Palabras clave}

Yo pienso, yo soy, Romanticismo, ciencia, vida, razón

\footnotetext{
Estudiante de séptimo semestre de la Facultad de Filosofía de la Universidad Santo Tomás.
} 


\begin{abstract}
In the present text I will argue about the achievements of the authonomy of the modern human being, asserted from the beginning by the cartesian cogitus, getting in contradiction, and therefore in crisis, with poetes and philosophers from the XVIII century, whom seek for self-affirmation from a concrete egotism, it may be understood either in an inclusive perspective towards totality or in the contrary perspective fixed for the isolation of the 'ego' in relation to the 'whole'. The development of the present work, will start with the teleologic contributions made by Goethe in the science field. Adding to this purpose the text 'The Most Ancient Programme of the German Idealism System'. This text is attributed to the early years of Hegel, Schelling and Holderlin and represents a future aspect of the german idealism which has clear pretensions to bodily the rational authonomy of the modern human being. Finally, I will approach to the disillusion phenomenon caused by the ego's irrealization in the totality, remaining as a scrap of existance the 'I am' of the romantic human being. For this purpose, I have made use of Kierkegaard and his contibutions to the problem of self-consciousness and the figure of Raskolnikov, the main character of Dostoievsky's work: Crime and Punishment.
\end{abstract}

\title{
Key words
}

I think, I am, romanticism, science, life, reason

"Pienso luego soy", no puede querer decir sino "pienso luego soy pensante"; ese ser del soy, que se deriva de pienso, no es más que un conocer; ese ser es conocimiento, más no vida y lo primitivo no es que pienso, sino que vivo, porque también viven los que no piensan. Aunque ese vivir no sea un vivir verdadero. ¡Qué de contradicciones, Dios mío, cuando queremos cazar la vida y la razón!

Unamuno. Del sentimiento trágico de la vida.

\section{Problemática}

El poeta romántico y el filósofo idealista del 1800 en Alemania apreciaron la avasalladora fuerza del conocimiento científico extendiéndose indiferente hacia las distintas capas de la existencia humana. "El árbol de la ciencia” fue la metáfora predilecta para referirse al fenómeno de la proliferación de saberes. Con el crecimiento de este árbol también se indicaba que la especialización de las dis- tintas ramas del saber era una realidad. Con la multiplicación de las distintas ramas científicas,

(...) los conocimientos se fueron desarrollando a tal velocidad que no había persona capaz de seguirles la pista a todos. Entre tanto, los laboratorios que hasta entonces habían sido monopolio de los filósofos naturales particulares, pasaron a ser obra y dotación de las uni- 
versidades, haciendo asequibles los métodos experimentales de estudio no sólo a los investigadores de profesión, sino a los mismos estudiantes. La facilidad que daba esto para consagrarse más por entero al estudio a fondo de cada asignatura dejaba menos tiempo para panorámicas generales, con lo que los hombres de ciencia corrían el peligro de "no ver el bosque por los árboles².

Efectivamente, con el fenómeno que implicaba el crecimiento del árbol de la ciencia, el conocimiento humano, en lugar de ser el signo de una totalidad que se funda en la comprensión que alcanza de sí misma cuando se articula en cada una de sus partes constituyentes, dio el paso hacia una carrera que se aventuraba a descubrir objetos y campos de estudio nuevos. Entre mayor distancia tomaran de aquel centro orgánico los descubrimientos, serían mucho más fructíferos. Como principio epistémico de la atomización del árbol de la ciencia, se encuentra el dualismo que legó el cogito cartesiano a la autonomía del hombre moderno, declarado como un ser libre en su racionalidad.

Sin embargo, cabe preguntarse: ¿En dónde ha parado su corporeidad orgánica y vital? ¿Qué de su participación hacia la totalidad? ¿Qué sucede con las necesidades reales de una autonomía emancipatoria, ahora subordinada a una mecánica automatizada?

Un registro de este contexto lo proporciona Schiller en sus Cartas sobre la educación estética. En este texto es relatado el desgarramiento entre el individuo y la totalidad. Esta fractura del espíritu se entiende de esta manera: como los intereses privados no se ven reconocidos ni articulados por el interés público, surge el fenómeno más inmediato a esta relación excluyente y es el aislamiento de la parte, del individuo. Esto quiere decir que la fragmentación es el sello que identifica la situación del hombre en el tiempo moderno y que se hace reconocible desde todas las esferas circunstanciales en las cuales se halla involucrado. Para acentuar el sentido de la fragmentación del hombre moderno, Schiller recurre a un simbolismo entre contextos diferentes.

Dice Schiller que en comparación con el mundo griego, en donde el individuo hacía parte de la totalidad y en consecuencia el hombre bajo el rol del ciudadano se identificaba con el todo haciendo parte de un cuerpo orgánico formado por la naturaleza "que todo lo une”, el mundo moderno se identifica a través del símbolo de la máquina, que, formada por el entendimiento analítico "que todo lo divide”, no ha hecho más que distanciar a los individuos unos de otros, gestando en ellos, no un espíritu de fraternidad, sino de competencia declarada. El ciudadano de la polis, que simbolizaba la relación vital entre la parte y el todo, desaparece con el advenimiento de un hombre-máquina, símbolo del aislamiento y fractura entre la parte y el todo.

Ciertamente, no era de esperar que la sencilla organización de las primeras repúblicas sobreviviera a la sencillez de las primeras costumbres y relaciones sociales, pero en lugar de elevarse a una vida orgánica superior, cayó en una mecánica burda y vulgar. Aquella naturaleza multiforme de los estados griegos, donde cada individuo gozaba de una vida independiente y, cuando era necesario, podía llegar a identificarse con el todo, cedió su lugar a un artificioso me-

2 Cecil William Dampier, Historia de la ciencia y sus relaciones con la filosofía (Barcelona: Tecnos, 1989) 313. 
canismo de relojería, en el cual la existencia mecánica del todo se forma a partir de la concatenación de un número infinito de partes, que carecen de vida propia”3.

Con la escisión del hombre moderno, el poeta y el filósofo alemán formulan la reintegración como una forma de superar la contradicción existente. El primero lo hace por medio de la intuición poética. Esta intuición capta el absoluto, es decir, la totalidad infinita del hombre en su dinámica vital.

Al respecto, Hegel en su estética reconoce que esta intuición o idea estética, es un elemento que emparenta la poesía con el estudio de lo más general. Como ya lo había declarado Aristóteles en la poética, el carácter ficcional de lo poético, frente a los otros elementos que distinguen las formas literarias en la épica o en la tragedia, hace que este arte sea más filosófico en tanto que más se aproxima a la generalidad. Aunque los métodos difieran en torno a las orientaciones que en ambas regiones del espíritu se tiene hacia la universalidad, pues mientras que la universalidad a la que tiende la filosofía está mediada por la prolongación discursiva y el concepto, en la poesía esta generalidad es elaborada a partir de la brevedad de la palabra poética que persigue la idea, pues, “(...) la poesía representa de una manera general, por el hecho mismo de que su modo de expresión es la palabra. La esencia de la palabra es resumir y abstraer. En general, la poesía debe recoger solamente el elemento enérgico, esencial, significativo; y este elemento es precisamente el ideal, no aquello que ha sido dado simplemente como real, lo cual sería insípido y fastidioso de reproducir en todos sus detalles"4.

Lo fragmentario que aparece en la insípida realidad prosaica ha de ser poetizado, reunido en la brevedad que como palabra intuida persigue la idea. Un notable ejemplo acerca de esta brevedad lo ofrece Novalis, quien sintéticamente reúne el propósito común del poeta y del filósofo: superar la escisión del panorama real que ha descrito Schiller:

Nuestro pensamiento ha sido hasta el momento o bien puramente mecánico, -discurso-atómico-, o bien puramente intuitivo-dinámico. ¿Ha llegado el momento de la unión? (...) Si la filosofía, por medio del sistema y el estado, refuerza las energías del individuo junto a las de la humanidad y el cosmos, y convierte el conjunto en órgano del individuo y el individuo en órgano del conjunto, lo mismo ocurre con la poesía en relación a la vida. El individuo vive en el conjunto y el conjunto en el individuo. Por medio de la poesía surgen la mayor simpatía y la coactividad más intensa, la comunidad íntima de lo finito y lo infinito ${ }^{5}$.

Por este mismo empeño poético filosófico, se destacan Hölderlin en su Hiperión, o Goethe en sus estudios sobre la naturaleza. Empero, Novalis alude al sistema filosófico como forma conciliatoria entre el individuo y la totalidad. En este aspecto entra a jugar un papel muy importante Hegel. Con un mayor rigor sistemático, el Hegel adulto justifica la necesidad de construir filosofía allí donde los contrarios no han sido superados.

Friedrich Schiller, Cartas sobre la educación estética (Barcelona: Anthropos, 1990) 147.

G. W. F. Hegel, De lo bello y sus formas (Madrid: Espasa Calpe, 1977) 96.

F. Novalis, F. Schiller, A. Schelegel, H. Von Kleist y F. Hölderlin, "Fragmentos para una teoría romántica del arte”, Fragmentos logológicos, trad. Javier Arnaldo (Madrid: Tecnos, 1987) 136. 
El contexto histórico fracturado ${ }^{6}$ que describe Hegel en Creer y saber, lo habilita para construir un sistema conciliatorio, en el cual el hombre sea entendido, no como un fragmento, sino como una totalidad. Desde este punto de partida, el proyecto moderno gestado por el siglo de las luces, tiene que ser superado por la filosofía del espíritu, o mejor, por la idea absoluta.

Por su parte, se objetará que el proyecto sistemático hegeliano de una cosmovisión racional, construida a partir de la necesidad discursiva de mediar conceptualmente con la equivocidad que se desprende de la multiplicidad de la realidad, lo llevó a distanciarse de esa otra cosmovisión inmediata que se planteo con el intuicionismo romántico. Pero para Hegel las contradicciones del mundo sólo pueden ser superadas por una cosmovisión que reclame sistema filosófico, ya que "En la era moderna el espíritu ya no se puede quedar satisfecho con la interioridad del sentimiento, ni con la inmediatez de la experiencia estética, sino solamente con un pensamiento que sea saber absoluto (...)"”.

Pero, ¿si la praxis histórica le dijera a Hegel que después de su muerte el proyecto ilustrado no ha sido superado por el espíritu ab- soluto, y que más bien se ha consolidado hacia el positivismo? ¿Y que los antagonismos sociales no han sido superados por el sistema, y por lo demás, la individualidad no tiene otro refugio más que asegurarse a sí misma, porque la totalidad ha dejado de ser la utopía del bien público para convertirse en una realidad institucionalizada, hecha para masificar y extinguir las diferencias?

El Hegel sistemático al refutar la intuición romántica, continúa el proyecto ilustrado de la racionalización de todo lo real. Lo explica su fórmula "Lo que es racional es real, y lo que es real es racional", y, como lo había pensado Descartes al lado de estufa, la autonomía del hombre se define por su racionalidad; en Hegel se define por ser una emanación del espíritu absoluto. Y pregunto: ¿la corporeidad del hombre? ¿su particularidad?... Frente a la negación del espíritu absoluto de todo lo real y particular, en su propósito por llegar a capas más altas de la realidad, la voz del poeta romántico reacciona ${ }^{9}$ :

(...) Según Hegel, el espíritu es el sujeto que se ha hecho sustancia, que ha redimido a todo lo finito y lo ha reconciliado sistemáticamente. La exigencia que de este modo se plantea al hombre

6 A propósito del problema histórico que implica la escisión del espíritu del hombre en la época modera, tenemos la siguiente síntesis de lo que para el filosofo alemán significaba esta fractura: "La ilustración extiende su actividad reflexiva en todas las direcciones sin límite alguno. En el campo de la teoría, define el universo como una totalidad mecánica en la que sus partes originalmente separadas y contra distintas se relacionan unas con otras mediante los meros vínculos externos de causalidad. Se convierte así en el reino de lo explicable y calculable, en aquello que puede ser explicado mediante meros nexos causales y que en consecuencia, puede ser calculado en números y proposiciones. Constituyendo un mundo, que pueda ser confiado a la inteligencia artificial de los ordenadores y robots”. Este texto pertenece a Luis Alberto Restrepo, bajo el titulo “Génesis, consumación y superación de la modernidad según Hegel”. El texto aparece en el estudio introductorio a la obra de Hegel Creer y saber publicada por la editorial Norma de Bogotá en la colección Cara y Cruz, 1994.

Daniel Innerarity, Hegel y el romanticismo (Madrid: Tecnos, 1993) 15.

$8 \quad$ G. W. F. Hegel, "Prefacio", Principios a la filosofía del derecho (Buenos Aires: Sudamericana, 1989) 23.

9 La vitalidad del hombre poeta lo aqueja con mayor insistencia en el amar, odiar o en el querer, más que la propia razón. Allí toma cuerpo una autonomía preconceptual que se siente libre y a la cual le es indispensable actuar en la poiesis que implica el crear. Frente a lo anterior son reveladoras las palabras de Ramón Xirau: "El hombre no es puramente razón: es ser y valer, odio y amor, simpatía y diferencia. Razón (logos), sin duda; pero también, como lo pensaba Platón, eros y aun, platónicamente, mito.” Ramón Xirau, Poesía y conocimiento (Madrid: Trotta, 1999) 338. 
consiste en salir de su interioridad e incorporarse a aquella totalidad del espíritu, a ese yo sustancial, pensado y actuado a partir de él. Pero los románticos criticaron a Hegel -una crítica a menudo olvidada tras la presentación inversa de Hegel como un crítico y superador del romanticismo- que esa totalidad del espíritu no era otra cosa que la vana presunción de una razón que creía poder hacerse cargo de la totalidad y variedad de la vida, exigiendo a cambio el sacrificio de toda particularidad. El derecho absoluto del espíritu universal constituye el límite y la debilidad del juicio hegeliano acerca del romanticismo, el punto en el que la obstinación de la subjetividad romántica sigue conservando su valor ${ }^{10}$.

El valor de la rebeldía romántica se declara libre en su concreción, no en su racionalización. La particularidad es su tragedia, pues allí ha de padecer la individualidad de una existencia fútil, no identificada con el bien público ni con el sistema. Sus querencias se enfrentan y son rechazadas por los deberes de la humanidad:

(...) Porque el adjetivo humanus me es tan sospechoso como su sustantivo abstracto humanitas, la humanidad. Ni lo humano ni la humanidad, ni el adjetivo simple, ni el adjetivo sustantivo, sino el sustantivo concreto: el hombre. El hombre de carne y hueso, el que nace, sufre y muere -sobre todo muere-, el que come, y bebe, y juega, y duerme y piensa, y quiere: el hombre que se ve y a quien se oye, el hermano, el verdadero hermano ${ }^{11}$.
Frente al hombre concreto que se hace a partir de la intuición poética, se presenta la fría frase de Novalis que encontramos en Granos de polen: "Buscamos en todas partes lo incondicionado y sólo encontramos cosas”.

En fin, nos acercaremos al Hegel de juventud y a sus compañeros de fórmula Schelling y Hölderlin, para explicar la efervescencia rebelde del período presistemático de la vida hegeliana, como la expresión más fiel, no tanto de un idealismo del conocimiento, como de un idealismo de la voluntad emancipatoria, en donde se encuentran sus fuertes contactos con lo poético, lo mítico y romántico; y en el que se siente una mayor necesidad por una razón práctica que por una razón teórica, por una mitologización de la razón, que por una reducción de lo existente a razón positiva y fragmentaria, en últimas, a la necesidad problemática de afirmar la autonomía corporal mediante una educación estética, que es una institucionalización del hecho artístico, y a su vez, es una materialización política de la auténtica conciencia de sí del hombre moderno. En este periodo de juventud de Hegel se asoma un ejemplo de lo que significa la inclusión del "Yo soy" estético a un "Yo pienso” total y sistemático representado por una nueva concepción del estado.

No antes traeremos al gran hombre Goethe, en donde encontraremos al entusiasmo estético encarando los estudios científicos sobre la naturaleza. Bajo el sentido de la integralidad entre lo artístico y lo objetivo, entre lo personal y lo impersonal, entre la intuición y el análisis, sobreviene la dialéctica organicista del todo y la parte y viceversa, mediante la cual ha de asumirse los estu-

Innerarity, Hegel ..., 16.

11 Miguel de Unamuno, Del sentimiento trágico de la vida (Barcelona: Altaya, 1973) 20. 
dios científicos de la naturaleza. De ello tenemos una precisa descripción por parte de Dilthey:

Goethe había sentido siempre poca inclinación, poco talento y poca confianza por la disgregación de la realidad viva y por las teorías que desarrollan sus contenidos parciales, por las pesadas argumentaciones de los filósofos y sus quintaesenciados pensamientos de pensamientos. Vivía siempre en la unidad de las cosas y en la estructura de sus partes para formar el todo (...). La naturaleza era para él algo omniviviente, significaba para él aquella fuerza de creación que sentía en sí mismo $(. . .)^{12}$.

Finalmente aludiremos al desencanto romántico. Formulado ya por Hegel en su estética, esta forma de insatisfacción alude a la especificidad del artista como una actitud existencial que se radicaliza a través de una toma de conciencia de sí desde la facticidad. Cuando la integridad se convierte en utopía, aparece la individualidad, cuando la autonomía es tan abstracta, hay una necesidad por materializarse en un yo consciente de su concreción temporal, y consciente de que hay que actuar para afirmarlo. Para lo primero acudiremos a la figura del yo kierkegaardiano, para lo segundo a la de Rascolnikov, protagonista de Crimen y castigo de Dostoievsky.

En suma, y con toda la agitación que presenta el período romántico, nos preguntaremos por los vínculos entre la vida y la razón, y aún más, por sus contradicciones no superadas (tal vez hasta la venida del Nazareno, como lo creyó Rascolnikov). Mi escrito gira preferentemente en torno al problema de la autonomía de la subjetividad moderna, en el momento de abrirse paso hacia el conocimiento científico. Por un lado quiere afirmar su libertad incluida en la totalidad, por el otro, esa totalidad se le presenta como una abstracción que le quita vitalidad y particularidad. Probablemente la cuestión se reduzca a la contradicción; pero es la antítesis lo que caracteriza a los pueblos latinos. Hegel nos lo recuerda en las lecciones de historia de la filosofía, al afirmar que en estos pueblos "no existe la totalidad del espíritu”, como sí aparece en "la intimidad del espíritu germánico”. En contraposición al recio carácter del espíritu germánico: "Estas naciones no han tenido la necesidad de satisfacer a la totalidad del espíritu, por que justamente su espíritu es presa de la desunión. El interés temporal y el espiritual son dos cosas distintas para estas naciones"13.

\section{Goethe: arte y ciencia}

El cultivo de una ciencia cualquiera, de la química, de la física, de la geometría, de la filología, puede ser, y aun esto muy restringidamente y dentro de muy estrechos límites, obra de especialización diferenciada; pero la filosofía, como la poesía, o es obra de integración, de concinación, o no es sino filosofería, erudición pseudo-filosófica.

Unamuno. Del sentimiento trágico de la vida.

De los multifacéticos roles que asumió Goethe durante el transcurso de su vida, nos hemos inclinado por dilucidar su peculiar sentido de acercarse a los objetos científicos. El trasfondo simbólico que comporta para el poeta el análisis científico, le quita a éste su metodología caracterizada por la ex-

\footnotetext{
W. Dilthey, Vida y poesía (México: F. C. E., 1953) 117.

13 G. W. F. Hegel, Lecciones sobre la filosofía de la historia, vol. II (Barcelona: Altaya, 1994) 664.
} 
perimentación disecadora y especializada. Frente a la división analítica que realiza el entendimiento del objeto de estudio, ha de sumarse la intuición ${ }^{14}$, que capta la totalidad. Para esto hay que recordar que Kant en Crítica del juicio ${ }^{15}$ establece una diferencia fundamental entre el modo como la ciencia lleva a cabo el principio de causalidad y el modo como lo hace la estética mediante el principio de causalidad teleológica.

Desde el conocimiento científico el principio de causalidad marcha bajo la mecánica de la relación biunívoca de la causa y el efecto. En esta mecánica los objetos se aprecian como partes aisladas que el entendimiento ha dividido para realizar su análisis. La facultad por medio de la cual se comprende el principio de causalidad es el entendimiento.

El entendimiento se manifiesta a través de la vía mediática de la discursividad, caracterizada por ser contingente, ya que enmarca los límites del conocimiento humano. Por nuestra constitución se considera al todo real como el efecto de las fuerzas motrices que generan las partes. Mientras que en el entendimiento discursivo el principio de causalidad determina el orden de los objetos de la naturaleza a partir, no del todo, sino del funcionamiento de las partes que la explican causalmente, en el entendimiento intuitivo o intuición intelectual el principio teleológico aplicado a la comprensión de los objetos de la naturaleza los comprende no como partes aisladas, sino como verdaderos cuerpos que tienen vida y que además mantienen un vín- culo final y no causal con un todo orgánico que más que explicarlas, las fundamenta.

Esta última forma de inteligencia en la que las partes no son posibles sin antes haber una intuición del todo, se denomina prototípico o arquetípico. Si el entendimiento humano quiere tomar el todo como fundamento de las partes, no será el modo del entendimiento discursivo el que le permitirá hacer este paso, sino una representación que articule en un todo tanto el enlace de la partes al todo como el fundamento de estas últimas. Y este modo de enlace se denomina causalidad final.

De esta manera la influencia que ejerce la segunda parte de la Crítica del juicio de Kant sobre el modo como Goethe aborda los estudios de la naturaleza es decisiva. Con la forma de causalidad teleológica se funda una manera estética de asumir el acto cognitivo y es por medio de la intuición. Lo que reclama esta forma de conocimiento es una armonía que enlace simbólicamente la parte con el todo, y viceversa:

\section{Al estudiar la naturaleza \\ prestad atención a lo individual y al todo; \\ nada hay dentro, nada hay fuera; \\ lo que está dentro está fuera. \\ Sin perdida de tiempo, alcanzarás \\ santos y claros misterios ${ }^{16}$.}

14 En un artículo apasionante, titulado "La crítica de Goethe y Hegel a la teoría de los colores de Newton”, por Karen Gloy, se dice: "El fenómeno aprendido intuitivamente irradia más allá de sí, por cuanto es la expresión comprimida de una determinada conexión de sentido. A diferencia de la concepción separadora y disecadora, nos encontramos aquí frente a una concepción simbólica, o mística, tal como se conoce a partir del arte, la pintura y la poesía, la magia y el mito.” Estudios de filosofía (Universidad de Antioquia) 7-8 (1993).

15 Immanuel Kant, Crítica del juicio, trad. Manuel García Morente (Madrid: Austral/ Espasa, 1999). Ver la Segunda división, "Dialéctica del juicio teleológico”, parágrafo 76.

16 E. Imaz, El conocimiento científico (Madrid: Revista de Occidente, 1932) 126. 
Lo que irradia la totalidad de la naturaleza humana no puede someterse únicamente a la coacción de la legalidad experimental. El objeto de estudio ha de someterse al entusiasmo vital de quien investiga:

¡Qué pocos se sienten entusiasmados con lo que aparece sólo en el espíritu! Los sentidos, el sentimiento, la pasión, ejercen sobre nosotros un poder mucho mayor, y con razón, pues hemos nacido, no para observar y meditar sino para vivir $^{17}$.

La posición vital del investigador lo saca fuera de sí, lo sitúa dentro de un contexto histórico que lo determina. Sus querencias en el mundo se afirman no en un conocimiento desinteresado, si no en una necesidad vital por conocer. Las señales vitales, que no son racionalmente manifestaciones de una verdad plena, reconocen la previedad del conocer; ello implica simbolizar la dimensionalidad del hombre, esto es, juzgarlo como un ser que participa del mundo en su totalidad, y que lo vive prerreflexivamente. Los prejuicios indican el modo de conocer orgánico y holístico:

Todo lo que es opinión acerca de las cosas es individual, y sabemos de sobra que el convencimiento depende de la voluntad y no de la inteligencia; que nadie comprende nada que no le sea apropiado y, por esta razón, concede. En el saber y en el obrar, lo decisivo es el prejuicio que, como indica su nombre es un juicio previo a la investigación. Es una afirmación o negación de lo que corresponde o contradice a nuestra naturaleza; un impulso alegre de nuestro ser vital, lo mismo hacia lo verdadero que hacia lo falso, hacia todo aquello que sentimos estar en consonancia con nosotros ${ }^{18}$.

La pasión hacia la investigación científica, que arrastra al yo del poeta, al yo de carne y hueso, vislumbra una actitud estética que rechaza el anonimato que causa la relación biunívoca entre sujeto y objeto. La reducción experimental, al evocar este tipo de relación, desvincula la posición prerreflexiva del sujeto, del "Yo soy" en el mundo, fragmentándolo frente al todo orgánico de la naturaleza viva. Bien lo anota Goethe, que el convencimiento no se limita a la razón, sino que es conducido por la voluntad: El querer le ofrece valor y telos al conocer. Para el poeta "Es extraño, verdaderamente, que se trate de la ciencia como algo que existe por y para sí, cuando, en realidad, no es más que el mango y la palanca con que asimos y movemos al mundo" ${ }^{19}$.

El aislamiento de las partes en una eventual vida privada que se realiza de una manera distante al albergue de lo público, y que denunciaba Schiller en la educación estética del hombre, es introducida en Goethe, a manera de una cosmovisión del conocimiento científico. La especial relación que establece Goethe entre el estudio de la naturaleza y la estética tiene al fin moral como principal resultado de una cosmovisión artística del mundo fenoménico:

Es notable que Goethe describe la actividad del sujeto investigador con conceptos que parecen caracterizar más bien un proceso moral. En sus fórmulas se da la exigencia de instar al investigador a entablar una especie de relación comunicativa con la naturaleza, es

17 Goethe, Teoría de la naturaleza (Madrid: Tecnos, 1997) 4.

18 Imaz, El conocimiento ..., 122-123.

19 Imaz, El conocimiento ..., 130. 
decir, considerarla como una totalidad viva y no como un mecanismo. Cuando Goethe no quiere preguntarse "por las causas", sino por "las condiciones bajo las cuales los fenómenos se manifiestan”, se expresa el rechazo de una ciencia natural con el objetivo de dominar la naturaleza ${ }^{20}$.

La conexión entre la parte y el todo surge también en el momento en que el conocimiento científico es sinónimo de poderío para el individuo burgués. Su aislamiento responde a la naturaleza partida de su autonomía, que inclinada hacia la racionalidad, y por lo tanto alejada a la idea de una sociedad que vincularía su ser vital hacia la totalidad, toma lo principal, a saber, el estudio científico de toda la realidad por lo fundamental.

Y es allí donde entra la estética idealista, en el “(...) esfuerzo epocal por superar el aislamiento y desesperación que de él resulta”21. Con el propósito de vivificar los procedimientos comunes de la ciencia experimental, pueden entenderse los aportes de Goethe dentro del proyecto estético idealista.

Al imprimirle vida a los estudios de la naturaleza se afirma un principio fundamental que hace eco dentro del escenario científico de hoy. Este principio vital consiste en humanizar las condiciones sobre las cuales se construye la autonomía disciplinar y especializada de la ciencia, que cada vez se cierra a sí misma en una férrea racionalidad positiva. De esta manera tanto ciencia como poesía señalan la necesidad del pensamiento simbólico. Y este símbolo es la representación que hace el sujeto al enfrentarse al mundo fenoménico.

El símbolo que adviene por la emergencia de comprender el mundo de la naturaleza a partir de un principio de causalidad final y no simplemente a partir de un principio de causalidad mecanicista, permite que los objetos de la naturaleza abandonen el ropaje de la corporalidad móvil y cíclica, para tomar el disfraz de lo simbólico, un disfraz que da lugar a comprender la realidad como si se tratara de un organismo vivo. Sobre la organicidad del mundo se tienen los mejores ejemplos en las producciones simbólicas de las diferentes culturas, en las cuales subyace una noción del hombre y del mundo a partir de la gran metáfora de la creación que significan los mitos en los que se explica el origen del universo.

Con la cosmovisión organicista de Goethe, el límite del análisis y del escrutinio causal lo determina la síntesis de causalidad final que se realiza mediante la actividad intuitiva; capacidad por medio de la cual la conciencia concibe la creación del mundo en analogía con la creación de un cuerpo con vida propia. Esta intuición no solamente hace referencia a la capacidad cognitiva que genera el artista cuando pasa el pincel o la pluma sobre la tela o el papel, sino que es también una gran analogía que funda una cierta visión de la naturaleza a partir de un ser que actúa como el creador de todo lo existente.

Sin embargo, los esfuerzos se agotaron en el momento en que el progreso de las ciencias exactas dentro de la sociedad burguesa tomó fuerza:

Mientras que el pensamiento intuitivo de Goethe, basado siempre en el sentimiento de la unidad del universo, tenía que revelarse extraordinariamente fructífero y servir de acicate a los descubrimientos en el campo de las ciencias naturales orgánicas, era natural que las ciencias naturales matemáticas le resul-

P. Burger, Crítica de la estética idealista (Madrid: Visor, 1996) 36.

21 Burger, Crítica de la estética ..., 40. 
tasen perfectamente extrañas e inasequibles. En ellas, el entendimiento disuelve lo intuitivo de los fenómenos; construye relaciones matemáticas sobre un algo objetivo que no entra en alguna experiencia directa. El destino histórico de Goethe le llevaba a odiar y combatir la ciencia mecánica de la naturaleza, pero sin poder contener su progreso $^{22}$.

\section{Un proyecto de juventud}

La razón ya cumple con su contenido encontrando y exponiendo la ley. La animosa voluntad y el vivo sentimiento deben encargarse de ejecutarlo. Para poder vencer en su lucha contra las fuerzas naturales, la verdad ha de convertirse en una fuerza y crear un impulso que la represente en el reino de los fenómenos, por que los impulsos son las únicas fuerzas motrices del mundo sensible. Si hasta ahora la razón había dado tan contadas muestras de su fuerza victoriosa, no es porque el entendimiento no haya sabido ponerla de manifiesto, si no porque el corazón la desoyó y el impulso no actuó en su favor.

\section{Schiller, Cartas sobre la educación es- tética}

La idea de Schiller según la cual la voluntad del hombre es aquella dimensión humana que da fuerza, impulso y vida a la razón, le confiere un puesto importante a la libertad dentro del imperativo metodológico del cálculo que se manifiesta en el análisis empírico de la naturaleza. Este puesto que ocupa la vo- luntad en la naturaleza humana es el mismo que da lugar a tomar al hombre como un ser que se emancipa por el espíritu de la realidad que impone el mundo objetivo y mecánico.

Por otro lado, el principio de una moral heterónoma que impele al individuo a conformarse a las costumbres del pueblo y a todo aquello que tiende a convertirse en un hábito esclavizante y en artículo de fe, ha de cambiar por el derecho cuestionante de no acomodarse a la regla tradicional.

De ahí la enfermedad del romántico en no soportar la regla de lo clásico; su estado saludable es motivo de insatisfacción y rebeldía juvenil. El tono de Novalis al respecto declara una inclinación más pronunciada hacia la particularidad romántica que hacia la universalidad de lo clásico, pues en esta última forma artística el interés propio no se halla: "El individuo solo interesa, por ello nada de lo clásico es individual”23.

La estética idealista no se orienta en favor de una prosaica razón, como sí en el de una acalorada voluntad poética. La razón práctica como orientación de la explicación científica se caracteriza, por ejemplo en el Hegel de juventud, no por reducirse a una fórmula abstracta, al modo formal que exige la universalidad del imperativo categórico, sino por hacerlo a su modo vital, es decir, al modo de la necesidad. Y no sólo este elemento se encuentra en Hegel; piénsese en la necesidad de Schiller y también de Schelling, por una educación estética, esto es, por una necesidad social de institucionalizar el arte, en la cual se tenga por telos armonizar los intereses individuales con los públicos, la parte con el todo y el todo con la parte.

22 W. Dilthey, "Vida y poesía”, Goethe y la fantasía poética (México: F. C. E., 1953) 173-174.

23 F. Novalis, F. Schiller, A. Schelegel, H. Von Kleist y F. Hölderlin, "Fragmentos para una teoría romántica del arte”, trad. Javier Arnaldo, Granos de polen, Aforismo 55 (Madrid: Tecnos, 1987) 51. 
El derecho de afirmar la autonomía en su viva integralidad con el todo, responde aquí al texto titulado "Primer programa de un sistema del idealismo alemán”24, atribuido a los hombres F. W. J. Schelling, F. Hölderlin y G. W. F. Hegel. No es nuestro interés estudiar a quién de los tres amigos corresponde su autoría, sólo nos limitaremos a resaltar aquellos aspectos que refuerzan la idea de una búsqueda por realizar la autonomía del "Yo pienso" y de la que partió la subjetividad moderna, en su forma más corporal, en este caso bajo un programa político.

Para llegar al término de lo planteado, rescataremos las tesis principales del "Primer programa de un sistema del idealismo alemán”. Pero antes es necesario aclarar el marco contextual en el que se gestó este texto. En la segunda mitad del siglo XVIII son constantes las protestas en torno a la concepción de una razón analítica, que orientada por los métodos de la ciencia positiva no poseía un fundamento absoluto para justificarla. Su gran metáfora, la máquina, ha conllevado entender el proyecto ilustrado en su ánimo fragmentario, es decir, en la reducción a mera quimera fantasmagórica del sueño, el mito y las creencias.

Frente a lo anterior, dos ejemplos reaccionarios de juventud. El primero lo tenemos en voz de Hölderlin, en el poema "El joven a sus juiciosos consejeros”. Es un pleno manifiesto metafórico contra el criterio analítico de los juiciosos consejeros. Durante el desasosiego del joven, en los primeros versos se pregunta:
¿Pretendéis que me apacigüe? ¿Que domine

este amor ardiente y gozoso, este impulso hacia la verdad suprema? $(. . .)^{25}$.

El todo del espíritu, expresado en su infinita libertad, traspasa el dominio de la verdad objetiva. En el terreno del espíritu los contrarios son la posibilidad para el combate interior, que la ciencia monolítica pretende superar:

$(\ldots)$ ¿Por qué moderar el fuego de mi alma

que se abrasa bajo el yugo de esta edad de bronce?

¿Por qué, débiles corazones, querer sacarme

mi elemento de fuego, a mí que sólo puedo vivir en el combate?(... $)^{26}$.

El espíritu reclama la simbólica del mito, en vez de la frialdad fragmentaria del juicio:

(...) ¡No intentéis detener los corceles del sol

y dejad que las estrellas prosigan su trayecto!

¡Y a mí, no me aconsejéis que me someta,

no pretendáis que sirva a los esclavos! $(\ldots)^{27}$.

El hombre poeta no quiere desterrar la convivencia que se arraiga en la naturaleza y en el entusiasmo. En el tribunal de la experi-

24 G. W. F. Hegel, “Primer programa de un sistema del idealismo alemán”, Escritos de juventud, trad. José M. Ripalda (México: F.C.E., 1984) 219-220. Por su parte, Daniel Inneararity afirma que este texto “...constituye el acta de fundación del idealismo alemán, su manifiesto programático.” Innerarity, Hegel ..., 37.

25 F. Hölderlin, Poesía completa, vol. I, trad. Federico Gorbea, edición bilingüe (Madrid: Libros Río Nuevo, 1978) 44-47.

26 Hölderlin, Poesía ..., 45.

27 Hölderlin, Poesía ..., 47. 
mentación, el juicio ha desterrado la proximidad del hombre con lo divino. Aquello fue una relación entre el genio inspirado y su hijo creador de versos, el poeta:

(...) Antaño se clavaba en la cruz al inspirado,

hoy lo asesinan con juiciosos e insinuantes consejos.

¡Cuántos habéis logrado someter al imperio de la necesidad!

\section{(...)}

Es inútil: esta época estéril no me retendrá.

Mi siglo es para mí un azote.

Yo aspiro a los campos verdes de la vida

$\mathrm{y}$ al cielo del entusiasmo.

Enterrad, oh muertos, a vuestros muertos,

celebrad la labor del hombre, e insultadme.

Pero en mí madura, tal como mi corazón lo quiere,

la bella, la vida naturaleza ${ }^{28}$.

El segundo ejemplo es Hegel, quien en sus escritos de juventud acerca de la religión cristiana, desborda todo un sentido orgánico de la vitalidad religiosa. Allí Hegel argumenta, que la articulación del individuo con el todo, se da dentro de un vínculo real y no concep- tual: “(...) en la Europa de hoy en día, donde los individuos no llevan en sí la totalidad del Estado, donde el vínculo que les une es puramente conceptual y se reduce al hecho de vivir todos juntos bajo el mismo derecho (...)"29.

Dentro de la visión vital que Hegel nos ofrece sobre la religión cristiana es de suma importancia la proximidad que religa a los seres humanos. Esta religación entre los hombres no responde a un principio formal que fustiga tal relación, sino a una filiación de tipo fraternal: "En efecto, la relación de un hijo con su padre no es una unidad conceptual, como por ejemplo, la unidad o el acuerdo de opiniones, la identidad de principios, etc. Se trata de una relación viva entre seres vivos, de una identidad vital”30.

Así mismo se comprende que el amor no se deja atrapar por la formalidad del principio, pues su participación en la organicidad de la vida cristiana no es apresada por una síntesis conceptual, que anularía las diferencias, pues lo total se identifica plenamente en la diferencia entre las partes ${ }^{31}$ :

El amor no es como la razón, cuyo poder determinante se opone a lo determinado. No es algo limitado, ni algo finito. Es un sentimiento, pero no un sentimiento particular. El sentimiento particular es sólo una vida parcial, no la vida total. La vida total, dispersada a través de los sentimientos particulares,

\footnotetext{
Hölderlin, Poesía ..., 47.

Kostas Papaioannou, Hegel (Madrid: Edaf, 1975) 125.

Papaioannou, Hegel, 154.

Para entender el sentido vital del cristianismo en Hegel, la siguiente explicación es muy esclarecedora: "La Ilustración ha tratado de criticar a la religión con la pretensión de abrir así el paso a la emancipación en otras esferas de la cultura: en la economía, en la política, en la moral... Pero no ha advertido que entre estos ámbitos existe una íntima colaboración. En este sentido la idea hegeliana de Sittlichkeit -de totalidad de la vida de un pueblo- es antiilustrada, alberga una pretensión de impugnar o superar los procesos modernos de diferenciación de las distintas actividades humanas. El grado de libertad de un pueblo tiene muy poco que ver con el desarrollo unilateral de una de sus esferas; está más bien en función de la armonía con la que se desarrollan todos los subsistemas particulares”. Innerarity, Hegel ..., 75.
} 
trata en vano de encontrarse a sí misma en el conjunto de la diversidad. No está esa vida total contenida en el amor como en una suma de sentimientos múltiples, particulares y separados ${ }^{32}$.

Estos ejemplos significativos permiten pensar que el problema de una racionalidad llevada hacia la extrema división, en la que la autonomía del hombre sólo es vista desde la superioridad positiva y no desde la totalidad, ha llevado al siglo XVIII a formularse el siguiente problema: “¿Cómo es posible reconciliar a un individuo particular con su comunidad política concreta y un orden cósmico general bajo las condiciones que ha producido la idea moderna de libertad?”33.

El texto "Primer programa de un sistema del idealismo alemán” es una respuesta al problema ${ }^{34}$. A continuación se presentarán las tesis fundamentales del texto.

\section{En torno a las tesis principales}

1. "La primera idea es naturalmente la representación de sí mismo como un ser absolutamente libre. Con el ser libre, autoconsciente, emerge, simultáneamente, un mundo entero (...)”35. La razón práctica ha de regular la razón teórica, y no al contrario. El espíritu ha de ser consciente de su libre autonomía, para así elevarse de lo natural. Su libertad emancipatoria no se reconoce bajo la reducción mecánica individualizada, pues la correspondencia con su estar en el mundo conlleva a tener presente la idea de la humanidad por delante: "Aquí descenderé a los campos de la física; la pregunta es ésta: ¿Cómo tiene que estar constituido un mundo para un ser moral? Quisiera prestar de nuevo alas a nuestra física que avanza dificultosamente a través de sus experimentos”36.

2. “(...) quiero mostrar que no existe una idea del Estado, puesto que el Estado es algo mecánico, así como no existe tampoco una idea de una máquina. Sólo, lo que es objeto de la libertad se llama idea. ¡Por lo tanto, tenemos que ir más allá del Estado! Porque todo Estado tiene que tratar a hombres libres como a engranajes mecánicos, y puesto que no debe hacerlo, debe dejar de existir ${ }^{37}$ ". La concepción mecánica del Estado carece del espíritu de la libertad, en tanto que niega una vida pública orgánica con los intereses del individuo, y en cambio afirma la determinación y yuxtaposición de privacidades. Con la máquina del Estado sobreviene la división y, en consecuencia, el desencanto entre la esfera de lo publico y la esfera de lo privado. La abolición del Estado-máquina se convierte en una utopía antiburguesa para románticos e idealistas alemanes.

3. “El filósofo tiene que poseer tanta fuerza estética como el poeta. Los hombres sin sentido estético son nuestros filósofos ortodoxos. La filosofía del espíritu es una

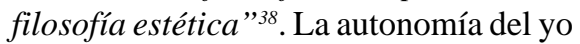
prosaico que se afirma por la simple ra-

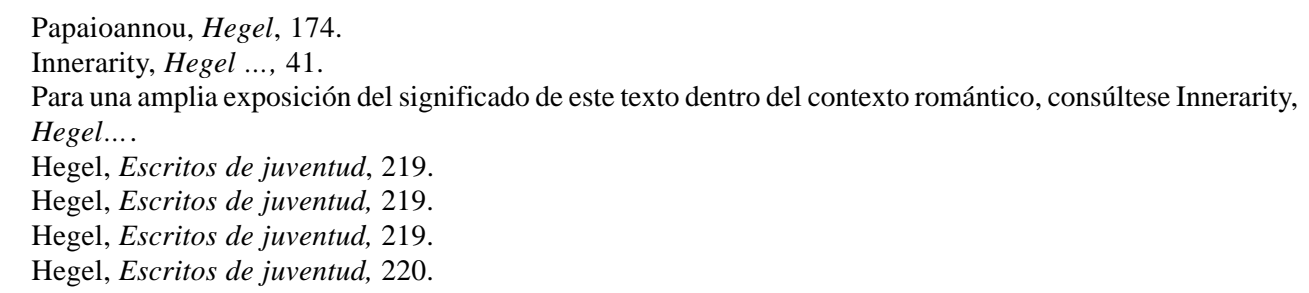


zón, o el yo que sobreviene de una postura ortodoxa de la filosofía ha de pasar al yo activo que eleva su espíritu por medio de la letra poética. En tanto que para la filosofía la existencia irreflexiva ha de ser negada, pues ella busca significar una realidad espiritual que esta más allá de la insípida objetividad, para la poesía romántica la realidad sin más ha de ser poetizada y elevada al nivel del espíritu.

4. "Mientras no transformemos las ideas en ideas estéticas, es decir, en ideas mitológicas, carecerán de interés para el pueblo y, a la vez, mientras la mitología no sea racional, la filosofía tiene que avergonzarse de ella. Así, por fin, los hombres ilustrados y los no ilustrados tienen que darse la mano, la mitología tiene que convertirse en filosófica y el pueblo tiene que volverse racional, y la filosofía tiene que ser filosofía mitológica para transformar a los filósofos en filósofos sensibles ${ }^{39}$ ". El carácter comunitario de la mitología es reflejado en el espíritu evocador que se desprende del simple hecho de contar historias. La mitología de la razón por su sentido evocador se plantea en principio reunir lo disgregado. La necesidad de síntesis por parte del espíritu romántico, ve en el mito el recurso simbólico y totalizador. Por su parte, el mito como filosofía y viceversa, es una dialéctica que está llamada a cons- truir la comunidad política. Esta comunidad se plantea “(...) sustituir la separación que ha sido introducida a través de la filosofía de la conciencia, del individualismo moderno y de la fría religiosidad protestante por la unificación del corazón”"40.

Las anteriores tesis, en tanto que proyectos no mediados por la realidad histórica, carecen de espacio referencial. En consecuencia describen los lineamientos de una utopía: la praxis histórica afirma con mayor contundencia la privacidad del individuo, que es un prefacio al atomismo social y, en sí a una concepción de la sociedad como un agregado mecánico de singularidades. Aquí mismo adviene la contradicción entre la vida y la razón ${ }^{41}$ : ¿resta, ya no indagar por una posible reunificación, sino por una afirmación de la propia existencia? Eso lo veremos a continuación.

\section{El desencanto romántico: una conciencia de sí concreta y activa}

El ideal poético es siempre un ideal falso, pues el ideal verdadero pertenece siempre a la realidad. Cuando el espíritu no puede tender el vuelo hasta el mundo eterno del espíritu, se detiene en el camino y se regocija contemplando las imágenes despejadas en las nubes, cuyo carácter efímero lamenta. La

39 Hegel, Escritos de juventud, 220.

40 Innerarity, Hegel..., 47.

41 "El alegato a favor del entusiasmo, la fantasía, el sentimiento, oculta el hecho de que el pensamiento romántico tiene que ser caracterizado como abstracto en una perspectiva determinada, precisamente porque establece la confrontación de los opuestos sin mediación. (...) Esta carencia de mediaciones con la realidad constituye por una parte la fuerza utópica de este pensamiento, pero por otra la catapulta fuera de la realidad. Precisamente por ello es un pensamiento predestinado, contra su intención, a ser el complemento ideal de una sociedad organizada por el capitalismo y administrada por la tecnocracia.” Burger, Crítica de la estética ..., 49. 
existencia de un poeta, como tal, es, por consiguiente, una existencia desgraciada; es superior a lo finito $y$, sin embargo, no es infinito.

Soren Kierkegaard, Estética y ética.

En el pecho del Fausto romántico ya no se alberga la totalidad del espíritu humano. El gran doctor se pregunta:

¿Qué soy entonces si no me es posible

alcanzar la corona de la humanidad

a la que tienden todos mis sentidos? ${ }^{42}$

Y el espíritu negador, Mefistófeles, le contesta:

Tú eres, a fin de cuentas..., lo que eres.

Ponte pelucas de millones de rizos,

calza tus pies coturnos de una vara de alto;

seguirás siendo siempre, sin embargo, lo que eres ${ }^{43}$.

El existir del hombre que antecede al pensar se sintetiza en la formula "soy luego existo". El desencanto romántico es un claro rechazo hacia el racionalismo de la modernidad, y aún más, una vuelta a la conciencia de sí en su particularidad, que no permite incluirse ni al sistema, ni al cogito, ni al espíritu absoluto. De cara al ethos de la autonomía representada por el yo artístico, en su más estrecha corporeidad, Hegel la señala como la causante de la decadencia del arte, frente a su antípoda, el arte clásico en donde se armoniza el elemento interior y espiritual al ele- mento exterior. Para la época, el movimiento artístico que con mayor insistencia expresaba una subjetividad rebelde y preocupada por la situación existencial del artista era el romanticismo:

En el arte romántico, en el cual el alma se retira en sí misma, todo lo que encierra el mundo exterior obtiene el derecho de desenvolverse separadamente, a mantenerse en su existencia propia y particular. Como el fin esencial de la representación es el manifestar la persona humana en sí reconcentrada, poco importan los objetos determinados del mundo físico o moral. Este principio puede, pues, manifestarse en las circunstancias más diversas, en medio de las situaciones más opuestas, en toda suerte de disgresiones y extravíos, (...), pues lo que se busca, lo que se quiere hacer resaltar, es el desarrollo subjetivo o personal del individuo, su manera de ser o sentir, y no una idea objetiva un principio general y absoluto ${ }^{44}$.

El tipo de conciencia de sí que presenta Hegel dentro de su sistema termina por ser un momento del espíritu absoluto. A consecuencia de la síntesis que reclama la lógica interna de la dialéctica se comprende este devenir de la conciencia. En cambio, la conciencia de sí en Kierkegaard, se da en un nivel de mayor concreción existencial. Lo importante cuando se afirma la autonomía del hombre es que ha sido producto de una vivencia propia $^{45}$. No pretendo aquí comparar en profundidad las posturas de Hegel y Kierkegaard frente a este problema, simplemente he que-

42 Goethe, Fausto (Bogotá: Casa Editorial El Tiempo, 1991) 71.

43 Goethe, Fausto, 71.

44 Hegel, De lo bello ..., 208.

45 Al respecto, las siguientes palabras de Juan Manuel Pons Juanpere, en su artículo "El momento de la repetición (a propósito de la teoría de la conciencia en Kierkegaard)”, resultan aclaratorias: "En efecto, no será construyendo un sistema del mundo, como hizo Hegel, como se puede dar respuesta a los problemas del existente, ese individuo que se interroga con angustia sobre el sentido de su destino. Su existencia no puede quedar resuelta en una abstracción, pues se trata de una realidad viva, y que debe saber vivirla 
rido señalar que lo que para el danés implica hacer parte de lo absoluto, es tanto como perder la particularidad que ofrece la vida poética romántica, la cual, afirmándose en el yo concreto, se desprende de las convicciones seguras que otorga el logos construido sistemáticamente. Con el enfrentamiento entre lo espiritual (yo pienso), y lo temporal (yo soy), sobreviene la paradoja y la contradicción.

Por otro lado, el lema de Rascolnikov, protagonista de la novela Crimen y castigo de Fedor Dostoievsky, podría sintetizarse en la formula kierkegaardiana según la cual "La verdad, es la vida misma quien la expresa: es la vida en acto". La acción maquinal de Rodia fue el crimen y este acto fue la expresión más fiel de una autonomía vivida en su plena inconsciencia. Sin embargo, no es tanto el definitivo final de la acción lo que nos importa, como más bien el principio justificador por el cual el protagonista obró. Este principio es, a mi parecer, la interesante reflexión que hace el personaje sobre el hombre extraordinario.

Pero antes señalemos un desencanto romántico. En el momento en que la vida pública (totalidad, pueblo, ciudad) se desgarra de la vida privada, no quedando más que individualidades atomizadas, se consolida el mundo burgués, clasificando al hombre en dos clases antagónicas claramente diferenciadas: la clase de los amos y la clase de los esclavos. En términos burgueses, nos referimos a los hombres ordinarios (proletarios) y a los hombres extraordinarios (burgueses). Los primeros se reconocen como masas ingentes, representantes de la rutinaria vida prosaica, los segundos como los verdaderos artistas y protagonistas de su propia existencia.

Una característica más: "Los hombres de la primera categoría -ordinarios- son dueños del presente; los de la segunda -extraordinarios-, del porvenir. La primera conserva un mundo multiplicando la humanidad; la segunda, empuja al universo para conducirlo hacia sus fines. Los dos tienen razón de existir" ${ }^{\prime 4}$.

Sí, tienen razón de existir, pero ¿quién posee el valor de actuar para romper las reglas y convertirse en un criminal? ¿ $\dot{\text { No representa }}$ una acción el momento que define el sentido de la propia existencia?...

La autonomía de la subjetividad moderna, representada por las personalidades que asumen su papel dentro del gran teatro del mundo, como las artísticas, filosóficas o científicas, y por todos aquellos que hacen algo para salir de una cotidianidad asfixiante procurando distinguirse de un control unánime y masificador, refleja la auténtica expresión vivencial de la conciencia de sí; pero también refleja su contradicción frente a una nostalgia del deber por la humanidad. La contradicción entre el "Yo soy" y el "Yo pienso" es la que se debate en el seno mismo del espíritu romántico: "El romántico quiere al mismo tiempo mantener el individualismo moderno y conseguir en la mitología y la religión el punto referencial que funda la unidad" ${ }^{\prime 7}$. Aunque la distinción inicial represente finalmente una aparente victoria de la individualidad burguesa sobre la totalidad de lo social, valga decir que esta totalidad ya

apasionadamente. No será, pues, objetivando (saliendo fuera de sí) como solucionará el enigma de su propio existir. Ante todo, piensa Kierkegaard, tratamos con sujetos”. Los antihegelianos: Kierkegaard y Schopenhauer (Barcelona: Anthropos, 1990) 81-99.

46 Fedor Dostoiewski, Crimen y castigo (Barcelona: Juventud, 1964) 275-276.

47 Burger, Crítica de la estética ..., 55. 
no es una metáfora del organismo vinculante, sino más bien un frío y prosaico sustantivo denominado muchedumbre o masa. Probablemente tendremos que esperar hasta la venida del Nazareno para confirmar la verdadera existencia armónica entre la totalidad y la parte. ¡Mientras tanto podemos pensar en el mundo griego!...

\section{Acotación final}

Nuestro problema no está resuelto por causa de la contradicción. Ambas perspectivas nos inclinan hacia la paradójica vivencia del ánimo romántico. Que al "Yo pienso” le salga al encuentro el "Yo soy”, surge como una necesidad de buscar conexiones entre ramas del pensamiento que se han identificado plenamente por sus diferencias, es decir, entre la filosofía, el arte y la ciencia.

Por otro lado, los constantes encuentros entre lo poético y lo filosófico que se dieron durante el desenvolvimiento de las ideas en el romanticismo, más que señalar bifurcaciones insalvables, lo que indican son senderos para abordar una nueva metafísica que la ciencia con sus metodologías cada vez iba desmoronando... ¿se podrá pensar en
Heidegger como el continuador de esta nueva metafísica?... Aquí no se trata de excluir estos dos principios de la subjetividad del hombre moderno para señalar finalmente el fracaso de un proyecto y la victoria de otro, sino más bien tener en cuenta que estas paradojas se desprenden naturalmente al tomar en consideración la reflexión filosófica del hombre en la modernidad.

Finalmente, asumo el ánimo inquietante que me causaron las dudas de Unamuno, y que consigno para que el lector emprenda también esta marcha hacia la comprensión del Yo:

La verdad es sum, ergo cogito, soy, luego pienso, aunque no todo lo que es piense. La conciencia de pensar, ¿no será ante todo conciencia de ser? ¿Será posible acaso un pensamiento puro, sin conciencia de sí, sin personalidad? ¿Cabe acaso conocimiento puro sin sentimiento, sin esta especie de materialidad que el sentimiento le presta? ¿No se siente acaso el pensamiento y se siente uno a sí mismo a la vez que se conoce y se quiere? ¿No puede decir el hombre de la estufa: “siento luego soy”, o "quiero, luego soy"48.

48 Unamuno, Del sentimiento trágico..., 50. 